\begin{tabular}{c} 
International Journal of Advanced Geosciences, $4(2)(2016) 72-75$ \\
SPC \\
Website: $\begin{array}{c}\text { www.sciencepubco.com/index.php/IJAG } \\
\text { doi: } 10.14419 / \text { ijag. } v 4 i 2.6511 \\
\text { Research paper }\end{array}$ \\
\hline
\end{tabular}

\title{
Production rate and cost comparison of ceramic block solar desalination unit (CBSDU) with basin type solar still (BSS)
}

\author{
Md Hamidul Islam ${ }^{1 *}$, Quazi Hamidul Bari², Md Shafiqul Islam \\ ${ }^{I}$ Lecturer, Dept. of BECM, KUET, Bangladesh \\ ${ }^{2}$ Professor, Dept. of Civil Engineering, KUET, Bangladesh \\ ${ }^{3}$ MS Student of Disaster Management, Dept. of Geography \& Environment, University of Dhaka, Bangladesh \\ *Corresponding author E-mail: hamidcekuet@gmail.com
}

\begin{abstract}
Distilled water for drinking purposes is vital especially in semi or arid countries where surface water is limited and groundwater is saline. The ceramic block solar desalination unit (CBSDU) is significant for single household in developing countries like Bangladesh. The aims of this study are to monitor daily production and cost compared with basin type solar still (BSS). The materials and installation cost of the ceramic block solar unit was estimated Tk.40 per solar desalination unit. The field experiment was carried out on the roof top of the civil engineering building, KUET from 24th February to 11th June, 2012. The CBSDU was installed perpendicular to the surface, from 2 feet above the surface, on a concrete base. The collection bottle was put under the concrete base. The distilled water was collected every day at least two hours after sunset. The average production was found $4.26 \mathrm{lit} / \mathrm{m} 2 / \mathrm{day}$. The CBSDU offers $12 \%$ less cost than BSS. Single household can easily use CBSDU for their drinking water in coastal belt of Bangladesh.
\end{abstract}

Keywords: Ceramic Block; Coastal Belt; Drinking Water; Production; Solar Desalination.

\section{Introduction}

Solar distillation has been in practice for a long time. The earliest documented work is that of the Arab alchemists in 1551. In their historical review on desalination of water, [1] the work of Della porta which he published in 1589. The great Frecnch chemist Lavoiser (1862) used large glass lens, mounted on elaborate supporting structures, to concentrate solar energy on the contents of distillation flasks. The use of silver or aluminum coated glass reflectors to concentrate solar energy for distillation purpose has been described by Mouchot (1869). The conventional solar distillation apparatus, commonly known as the solar still, was first designed and fabricated in 1872 near Las Salinas in Northern Chile by Carlos Wilson, a Swedish engineer. This was a large basin type solar still, meant for supplying fresh water to a nitrate mining community. Several wooden bays of size $1.14 \mathrm{~m}$ x $61.0 \mathrm{~m}$ were joined together to yield a total surface of area $4700 \mathrm{~m}^{2}$, which was covered with glass. The bottom of the bays, exposed to the sun, was blackened with logwood dye and dye.

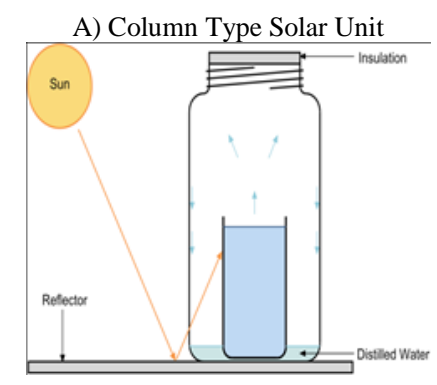

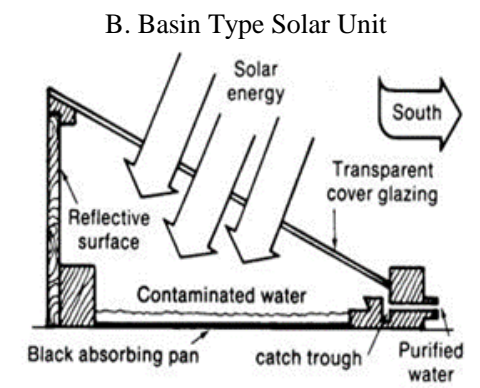

C. Sea Water Desalination

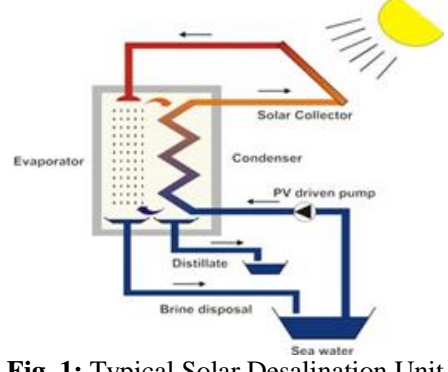

Fig. 1: Typical Solar Desalination Unit.

No work on solar distillation seems to have been published after 1880 till the end of the First World War. Use of metal coated reflections as a solar concentration for application in solar distillation has been described by Kausch (1920); Pasteur (1928) also used several concentrations to focus solar energy onto a copper boiler containing water. Abbot (1930) [2] used cylindrical parabolic reflectors to focus solar energy onto evacuated tubes containing water. During the Second World War (1945) developed air 
inflated plastic stills for the U.S. Navy and Air Force for use in the emergency life-rafts, as many as 200,000 of these stills were used by the Navy during the war.

The challenges of the 21st century are numerous such as climate change, increasing scarcity of fossil energy resources and the concentration of reserves in only a few regions of the world, scarcity of fresh water. About $97 \%$ of the earth's water is salt water in the oceans, and a tiny $3 \%$ is fresh water. Many areas worldwide that suffer from severe water scarcities are increasingly dependent on desalination as a highly reliable, nonconventional source of freshwater. Desalination markets have greatly expanded in recent decades and they are expected to continue expanding in the coming years, particularly in the Mediterranean, Middle East and North African (MENA) regions. The CBSDU is the most advance system of solar desalination especially used for single household. So, solar desalination is a crucial important in many coastal region because of the salinity of water. The main objectives of this study are to monitor daily production, make correlations for daily output and temperature, and compared with basin type solar still (BSS).

\subsection{Potential of solar energy in Bangladesh}

Bangladesh is located between $20^{\circ} 30^{\prime \prime}$ and $26^{\circ} 45^{\prime \prime}$ north latitude and the climate is tropical, the location makes Bangladesh good recipient of solar energy (Zaman M., Islam M.A., and Sarkar M.A.R, 2006). Bangladesh has a total area of $1.49 \mathrm{E}+11 \mathrm{~m}^{2}$ and an average of $5 \mathrm{kWh} / \mathrm{m}^{2}$ solar radiation falls on this land over 300 days per annum (Huque, S. and Mazumder, R. K., 2006). Maximum amount of radiation is available on the month of MarchApril and minimum on December-January [5]. The total solar energy reaching Bangladesh is $180 \times 109 \mathrm{Mwhr} /$ year which is 105 times the energy generated as electricity [3]. The monthly solar insolation at different locations of Bangladesh is given in table- 1 .

Table 1: Monthly Solar Insolation at Different Locations of Bangladesh (Kwh/M².Day) Recorded for 12 Months from 1988 to 1998 [5]

\begin{tabular}{lllllll}
\hline Month & Dhaka & Rajshahi & Sylhet & Bogra & Barishal & Jessore \\
\hline January & 4.03 & 3.96 & 4.00 & 4.01 & 4.17 & 4.25 \\
February & 4.78 & 4.47 & 4.63 & 4.69 & 4.81 & 4.85 \\
March & 5.33 & 5.88 & 5.20 & 5.68 & 5.30 & 4.50 \\
April & 5.71 & 6.24 & 5.24 & 5.87 & 5.94 & 6.23 \\
May & 5.71 & 6.17 & 5.37 & 6.02 & 5.75 & 6.09 \\
June & 4.80 & 5.25 & 4.53 & 5.26 & 4.39 & 5.12 \\
July & 4.41 & 4.79 & 4.14 & 4.34 & 4.20 & 4.81 \\
August & 4.82 & 5.16 & 4.56 & 4.84 & 4.42 & 4.93 \\
September & 4.41 & 4.96 & 4.07 & 4.67 & 4.48 & 4.57 \\
October & 4.61 & 4.88 & 4.61 & 4.65 & 4.71 & 4.68 \\
November & 4.27 & 4.42 & 4.32 & 4.35 & 4.35 & 4.24 \\
December & 3.92 & 3.82 & 3.85 & 3.87 & 3.95 & 3.97 \\
Average & 4.73 & 5.00 & 4.54 & 4.85 & 4.71 & 4.85 \\
\hline
\end{tabular}

\section{Methodology}

A prefabricated ceramic block solar desalination unit (CBSDU) for desalination purpose was installed, which was a water tight circular plastic jar of $14.61 \mathrm{~cm}$ diameter and $17.15 \mathrm{~cm}$ height. A water tight plastic cover was in the jar mouth. Two ceramic blocks (for lower block $7.62 \mathrm{~cm}$ diameter and $5.08 \mathrm{~cm}$ height, for upper block $8.89 \mathrm{~cm}$ diameter and $6.35 \mathrm{~cm}$ height) were placed inside the jar and on the plastic cup toward the mouth. A plastic pipe of $4.5 \mathrm{~mm}$ diameter was connected in the jar mouth to the collection bottle. The pores in the jar and around mouth were filled by gum. The distilled water was collected into a collection bottle. The temperatures were recorded by an installed thermometer. I have collected the water daily at least two hours after the sun set. The field experiment was carried out on the roof top of the civil engineering building, KUET from 24th February to 11th June, 2012. Also the four days hourly production rate was collected on 26th March, 22nd May, 2nd June and 11th June, 2012. Then production rate was estimated by collecting data. Finally, the production rate and cost has been compared with Basin type Solar Still (BSS).

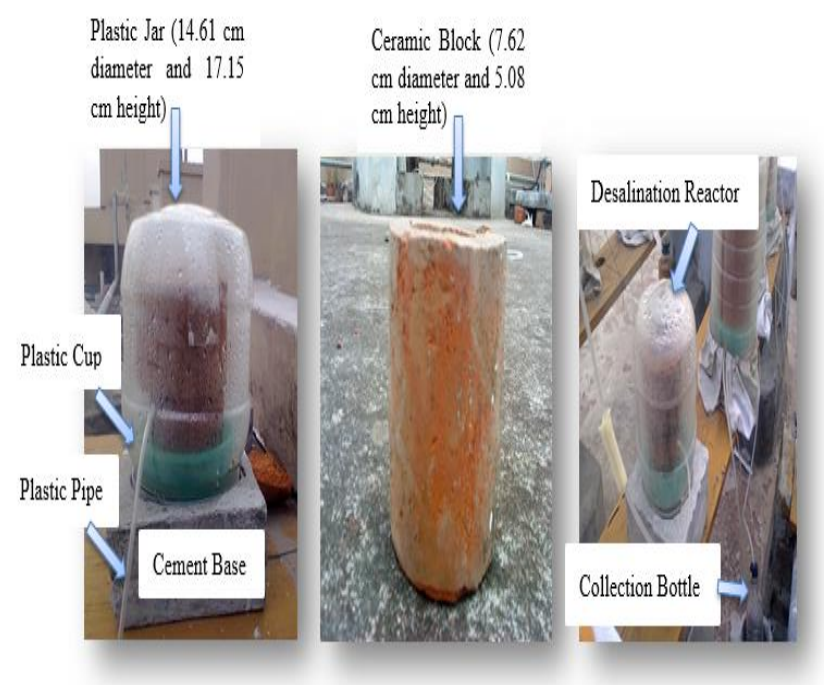

Fig. 2: Set-Up of Ceramic Block Solar Desalination Unit (CBSDU).

\subsection{Cost of ceramic block solar desalination unit (CBSDU)}

The materials and installation cost of CBSDU is calculated below in table- 2 .

Table 2: The Materials And Installation Cost Of CBSDU

\begin{tabular}{lllll}
\hline $\begin{array}{l}\text { Serial } \\
\text { No. }\end{array}$ & Item & $\begin{array}{l}\text { Number of } \\
\text { Unit }\end{array}$ & $\begin{array}{l}\text { Per Unit } \\
\text { Cost } \\
(\mathrm{Tk} .)\end{array}$ & $\begin{array}{l}\text { Total } \\
\text { Cost } \\
(\mathrm{Tk} .)\end{array}$ \\
\hline 01 & Cement base & 1 & 5.0 & 5.0 \\
02 & Plastic Pipe & 1 & 5.0 & 5.0 \\
03 & Plastic Cup & 1 & 5.0 & 5.0 \\
04 & Plastic Jar & 1 & 10.0 & 10.0 \\
05 & Ceramic Block & 2 & 5.0 & 10.0 \\
06 & Miscellaneous & -- & -- & 5.0 \\
Total Cost (Each CBSDU) $=$ & & & 40.0 \\
\hline
\end{tabular}

\subsection{Cost of basin type solar still (BSS)}

The construction cost for the Basin type Solar Still (BSS) is calculated Tk. 1000. The material cost of the BSS is shown in table- 3 .

Table 3: The Materials Cost of the BSS [6]

\begin{tabular}{|c|c|c|c|c|c|c|}
\hline Serial & No. & $\begin{array}{l}\text { Item Descrip- } \\
\text { tion }\end{array}$ & Unit & $\begin{array}{l}\text { Rate } \\
\text { (Tk.) }\end{array}$ & $\begin{array}{l}\text { Quali- } \\
\text { ty }\end{array}$ & $\begin{array}{l}\text { Total } \\
\text { (Tk.) }\end{array}$ \\
\hline 1 & & \multicolumn{5}{|c|}{ Ferro-cement basin: } \\
\hline- & Cement & & $\mathrm{kg}$ & 7.0 & 20.0 & 140.0 \\
\hline- & Sand & & $\mathrm{cft}$ & 50.0 & 1.0 & 50.0 \\
\hline- & GI net & & $\mathrm{rft}$ & 15.0 & 10.0 & 150.0 \\
\hline- & GI wire & & $\mathrm{rft}$ & $1 / 25$ & 40.0 & 50.0 \\
\hline 2 & & Trough & nos. & 30.0 & 6.0 & 180.0 \\
\hline 3 & & Glass & $\mathrm{sft}$ & 40.0 & 7.0 & 280.0 \\
\hline Misce & llaneous & -- & -- & -- & -- & 150.0 \\
\hline \multicolumn{6}{|c|}{ Total Cost $($ Per Unit BSS $)=$} & 1000.0 \\
\hline
\end{tabular}

\section{Results and discussion}

An elaborate theoretical study on ceramic block solar desalination unit (CBSDU) has been completed. A typical condensation model has been developed from this desalination project. 


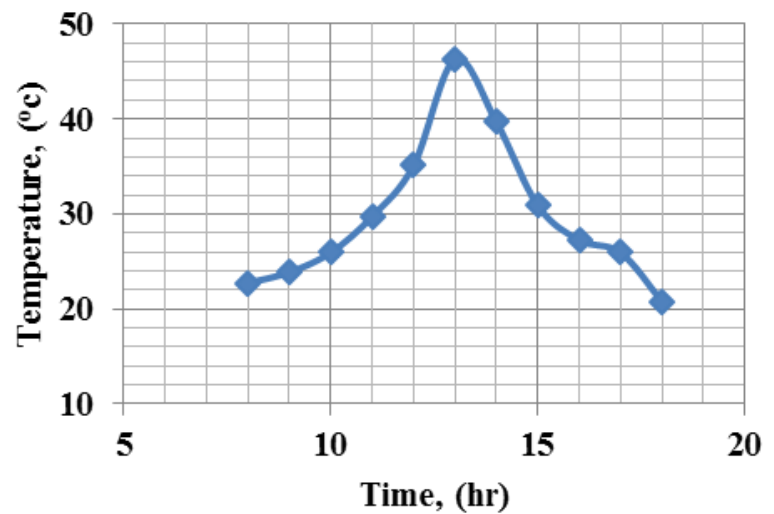

Fig. 3: Hourly Variations of Temperature for CBSDU.

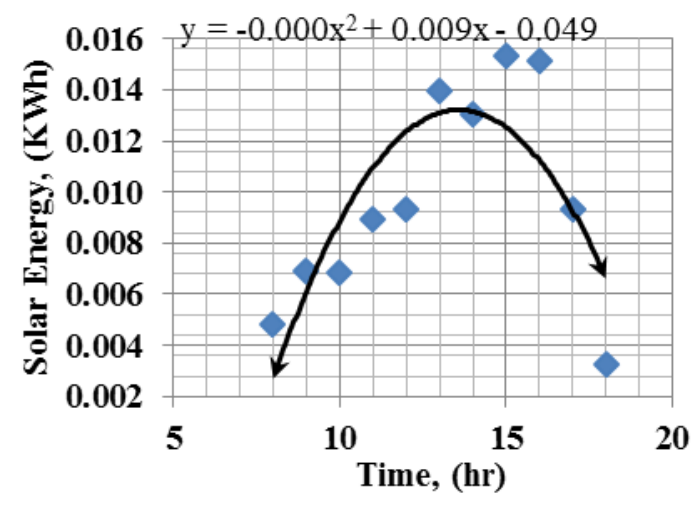

Fig. 4: Hourly Variations of Solar Energy for CBSDU.

The variation of temperature and solar energy with time has been shown in fig. 3. It given the simple model, $y=-0.000 x 2+0.009 x$ - 0.049. From this equation, we can calculate solar energy incident on a particular desalination unit in a various time. This model helps to design of particular desalination unit and make some correlations with hourly and daily productions.

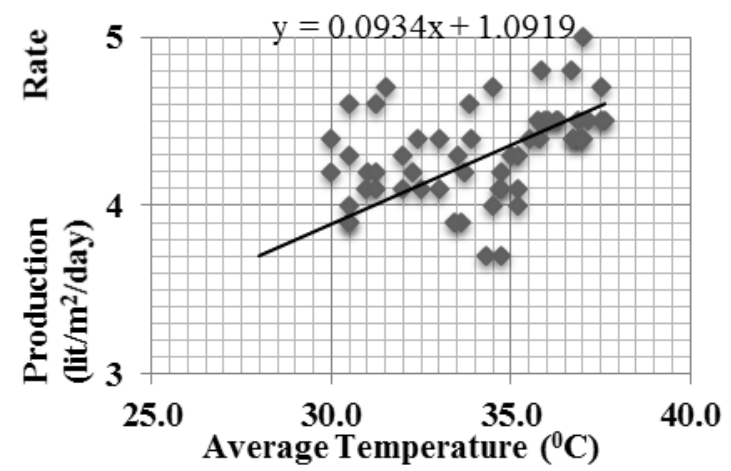

Fig. 5: Variations of Production Rate with Average Temperature for CBSDU.

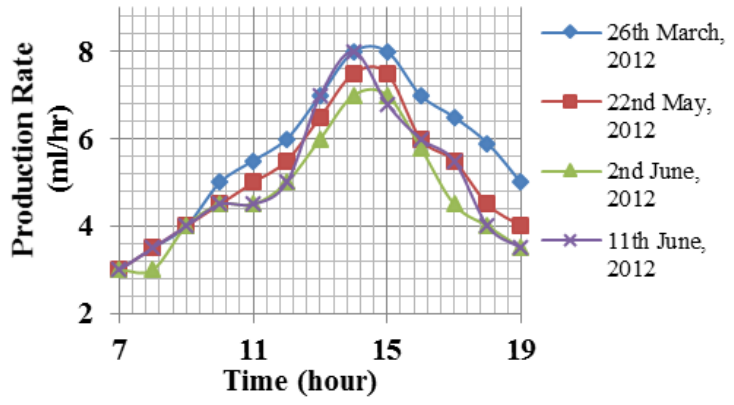

Fig. 6: Variations of Production Time (Right) for CBSDU.
The relationship between production rates of ceramic block solar desalination unit (CBSDU) to the average temperature from 24th February to 11th June, 2012 has been shown in fig. 4(left). The production rate increase with the increase of the temperature. From this experiment $\mathrm{I}$ found the production rate equation with average temperature, $\mathrm{y}=0.0934 \mathrm{x}+1.0919$; where $\mathrm{y}=$ production rate $(\mathrm{lit} / \mathrm{m} 2 /$ day $), \mathrm{x}=$ average temperature $(\mathrm{oC})$.

The variation of the production rate $(\mathrm{ml} / \mathrm{hr})$ on 26th March, 22nd May, 2nd and 11th June, 2012 respectively has been shown in fig.4 (right). All temperature rise rapidly in the morning, peak approximately $2.00 \mathrm{pm}$ to $2.30 \mathrm{pm}$ and then decline gradually, hence the production rate rise from the morning, reach at peak at $2.00 \mathrm{pm}$ to $2.30 \mathrm{pm}$ approximately, after that production rate decline to afternoon.

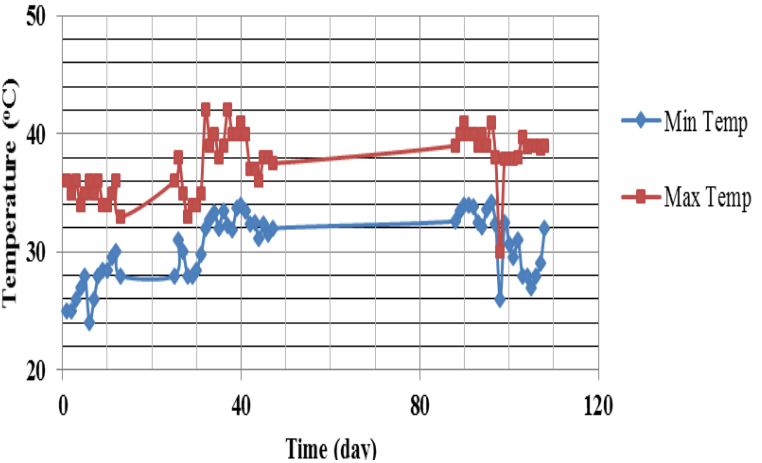

Fig. 7: Daily Variations of Temperature in Oc (24th February to 11th June, 2012).

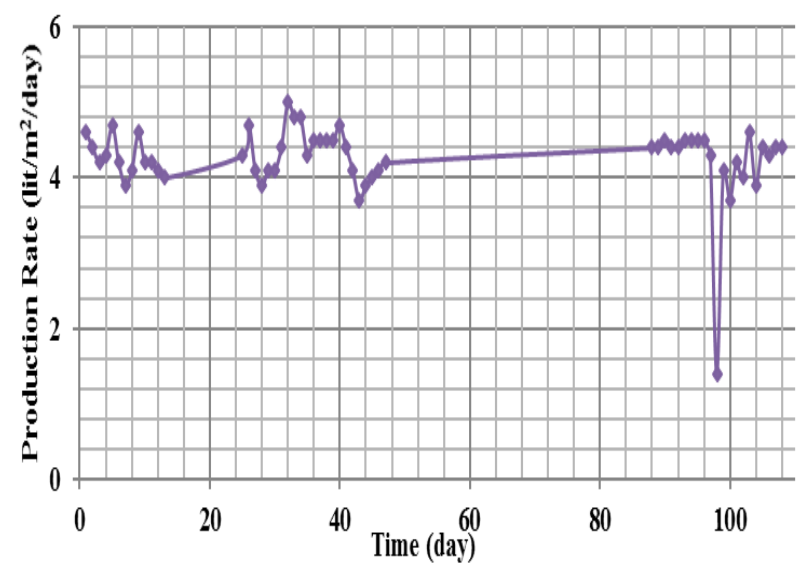

Fig. 8: Daily Production Rate of the CBSDU (24th February to 11th June, 2012).

The variation of daily maximum and minimum temperature from 24th February to 11th June, 2012 of the CBSDU has been shown in fig .5. The temperature varies from 24th February to 11th June, 2012 because of cold and warm front during a cold front, temperatures decrease because a cold air mass is taking place of a warm air mass. During a warm front it's the opposite. For liquids, when temperatures increase, the liquid will start to evaporate and when temperatures decrease, the liquid will start to condense or return to liquid state.

The daily production (lit/m2/day) of the CBSDU from 24th February to 11 th June, 2012 has been shown in fig. 6 . The daily production rate of a CBSDU is mainly depends on the intensity of solar radiation. It was found that the production is higher in sunny days; the production is lower in cloudy days. The production is proportional to the solar insolation. The average production rate from the collected date has been found $4.26 \mathrm{lit} / \mathrm{m} 2 /$ day. The average maximum and minimum production was found 4.6 and 3.9 lit/m2/day respectively. 


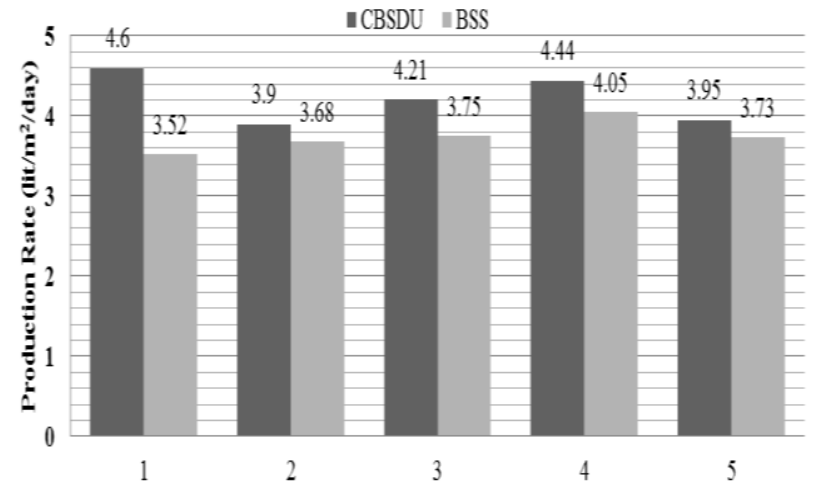

Fig. 9: Comparison of Average Production Rate between Ceramic Block Solar Desalination Unit (CBSDU) and Basin Type Solar Still (BSS).

Table- 4: Cost Summary of CBSDU and BSS

\begin{tabular}{ll}
\hline Type of Solar Unit & Cost per lit (Tk.) \\
\hline Ceramic Block Solar Desalination Unit (CBSDU) & 0.156 \\
Basin type Solar Still (BSS) & 0.200 \\
\hline
\end{tabular}

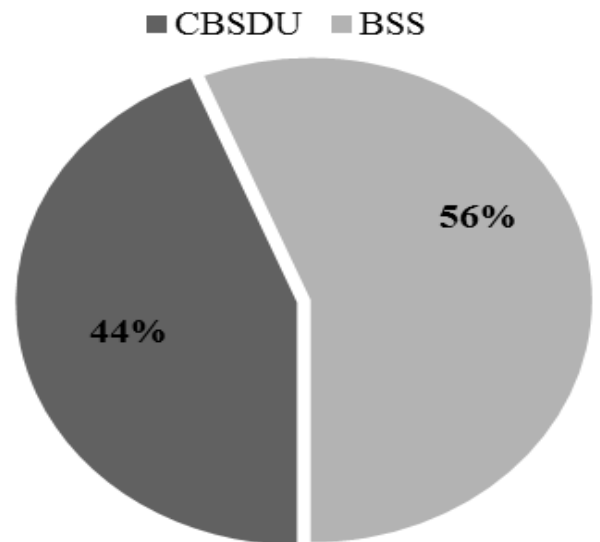

Fig. 10: Cost Comparison of Ceramic Block Solar Desalination Unit (CBSDU) with Basin Type Solar Still (BSS).

\section{Conclusions and recommendations}

Desalination using ceramic block solar desalination unit (CBSDU) can help to eliminate the pressure on coastal aquifers suffering from seawater intrusion. The average daily production rate of CBSDU measured $4.26 \mathrm{lit} / \mathrm{m}^{2} /$ day. The maximum and minimum production was found 4.6 and $3.9 \mathrm{lit} / \mathrm{m}^{2} /$ day respectively. The temperature of block dominates the production rate of CBSDU. Since the production rate of a solar still is mainly depends on the intensity of solar radiation. Hence the production rate will be higher in sunny and high temperature days. The comparative production rates have been measured higher in the month of February, March, April, May and June, 2012 than that of the basin type solar still (BSS). The CBSDU provides $12 \%$ less cost than BSS. The CBSDU is necessary for improving supply of fresh water. It is environmentally friendly and operating costs are low. It can be easily placed around the roof parapet wall, thus the effective use of roof space is ensured. Hence, for drinking and other purposes in remote, coastal and arid regions or in a crucial situation CBSDU is a better solution to meet the small scale of fresh water demand. For future research to get higher production rate a hybrid CBSDU could be designed using thin wall plastic jar that would also increase the distillate production rate.

\section{Acknowledgement}

Many thanks goes to technicians of laboratory of environmental \& geotechnical engineering, department of civil engineering, Khulna University of Engineering \& Technology (KUET), Khulna for their help in the CBSDU project.

\section{References}

[1] Nebbia, G. and Menozzi, G. (1996). A Short History of Water Desalination. Acqua Dolee Dal Mare, II Inchiesta Internazionole Milano, pp.129-130.

[2] Abbot, C.G. (1930). Smithsonian Inst. Coll., 98(5), Pub. No. 3530.

[3] Zaman M., Islam M.A., and Sarkar M.A.R. (2006). Solar Energy Insolation in Bangladesh, pp. 7-9.

[4] Huque, S. and Mazumder, R. K. (2006). Water Desalination Using Basin Type Solar Still. Undergraduate thesis paper, Department of Civil Engineering, KUET, Khulna, Bangladesh.

[5] Mondal, M. A. H. (2005). Monthly Solar Insolation at Different Locations of Bangladesh. Conference proceedings, CUET, Chittagong, Bangladesh, pp.29.

[6] Al-Anam, M. H. and Saha, S. R. (2009). Water Desalination Using Basin Type Solar Still. Undergraduate thesis paper, Department of Civil Engineering, KUET, Khulna, Bangladesh.

[7] Solar Radiation in Bangladesh. http://en.wikipedia.org/wiki/Radiation (Access date: 23.07.2011).

[8] Heat Conduction in Bangladesh. http://en.wikipedia.org/wiki/Conduction_\%28heat\%29 (Access date: 23.07.2011).

[9] Coastal Region Solar Desalination in Bangladesh: A Case Study in Khulna Region. http://apollo.lsc.vsc.edu/classes/met130/notes/chapter2/hcap (Access date: 26.06.2011).

[10] Solar Energy and Solar Desalination. http://pre.aps.org/ (Access date: 05.05.2011). 